\title{
Interaction of brain noradrenergic system and the hypothalamic-pituitary-adrenal (HPA) axis in man
}

\author{
Elizabeth A. Young*, James L. Abelson, Oliver G. Cameron \\ Department of Psychiatry and Mental Health Research Institute (EAY), University of Michigan, \\ 205 Zina Pitcher Place, Ann Arbor, MI 48109-0720, USA
}

Received 25 August 2004; received in revised form 21 December 2004; accepted 30 March 2005

\author{
KEYWORDS \\ ACTH; \\ Cortisol; \\ Noradrenergic system; \\ Stress; \\ Depression; \\ Anxiety disorders; \\ Social anxiety \\ disorder; \\ Growth hormone; \\ Clonidine
}

\begin{abstract}
Summary Background: Numerous interactions between the brainstem locus coeruleus system and the HPA axis have been shown in experimental animals. This relationship is less well characterized in humans and little is known about the influence of psychiatric disorders, which disturb one of these systems, on this relationship.

Methods: Untreated subjects with pure MDD $(n=13)$, MDD with comorbid anxiety disorders $(n=17)$, and pure anxiety disorders $(n=15)$ were recruited by advertising. Age and sex matched control subjects were recruited for each subject with a psychiatric diagnosis $(n=45)$. All subjects underwent a social stressor, the Trier Social Stress Test (TSST), and blood was collected for ACTH assay. These same subjects also underwent a clonidine challenge study for assessment of growth hormone release as a marker of tonic noradrenergic activation.

Results: Examining log transformed area under the curve response for each hormone, a significant negative relationship (simple regression) was observed between systems in normal subjects. This relationship was preserved in anxiety subjects. However, both pure depressed and comorbid depressed and anxiety subjects demonstrated disruption of this relationship.

Conclusions: Under normal circumstances, noradrenergic systems can influence the magnitude of the HPA axis response to stress. However, in subjects with major depression, HPA axis activation appears autonomous of noradrenergic influence.

(c) 2005 Elsevier Ltd. All rights reserved.
\end{abstract}

\section{Introduction}

Stress activates a number of systems including the hypothalamic pituitary adrenal (HPA) axis and the brain noradrenergic system controlling

\footnotetext{
${ }^{*}$ Corresponding author. Tel.: +1 734936 2087; fax: +1 734 6474130.

E-mail address: eayoung@umich.edu (E.A. Young).
}

autonomic output (Pacak and Palkovits, 2001; Sved et al., 2002). Both systems have been extensively studied in depression and anxiety disorders, although rarely in the same patient. Basic science data suggest these systems are linked via corticotropin releasing hormone (CRH) (Pacak and Palkovits, 2001; Sved et al., 2002). CRH and its receptors are widely distributed and central injection of CRH can mimic a generalized stress response (Dunn and Berridge, 1990). Stress activates 
the locus coeruleus (LC), where noradrenergic neuronal cell bodies are located, and this activation can involve CRH (Sved et al., 2002; Valentino, 1989; Aston Jones et al., 1991). CRH-mediated pathways connect the amygdala and LC (Curtis et al., 2002; Commons et al., 2003). LC neurons provide stimulatory noradrenergic input to the paraventicular nucleus (PVN); activation of the PVN leads to HPA axis activation and cortisol secretion (Curtis et al., 2002; Commons et al., 2003; Plotsky, 1987). Cortisol inhibits both the HPA axis and LC neurons, but it stimulates amygdala $\mathrm{CRH}$ neurons, which can result in excessive activation of the amygdala CRH system in the presence of hypercortisolemia (MC Ewen, 1995; Makino et al., 1994; Watanabe et al., 1995). Despite these extensive and important linkages observed in animals, links between these systems have been little studied in humans.

In humans, brain noradrenergic activity can be assessed only indirectly-for example, by measuring growth hormone $(\mathrm{GH})$ response to an adrenergic agent like clonidine (Abelson and Cameron, 1994). $\mathrm{GH}$ release is partially controlled by post-synaptic $\alpha 2$-receptors, and sensitivity of these receptors is modulated by tonic levels of LC output. GH response to adrenergic agents thus reflects tonic levels of noradrenergic outflow from the brain (Devesa et al., 1990, 1991). A blunted GH response to clonidine has been reported in both anxiety and depression (Charney and Heninger, 1986; Nutt, 1989; Uhde et al., 1986; Siever et al., 1982; Amsterdam et al., 1989; Charney et al., 1982) and interpreted as evidence for excessive central noradrenergic activity in these disorders.

Depression is accompanied by HPA axis activation and reduced sensitivity to negative feedback, while the HPA axis in anxiety disorders appears to be relatively normal (Young et al., 1991, 1993, 2000, 2004; Abelson and Curtis, 1996). Anxiety disorders are thought to involve activation of brain noradrenergic systems (Charney and Heninger, 1986; Nutt, 1989; Uhde et al., 1986), but whether this is the case in depression is less clear (Cameron et al., 2004). Given the complex linkages between LC and HPA axis described above, associations between HPA axis and noradrenergic measures should be expected in clinical studies. HPA axis activation and GH blunting have in fact been linked in a primate study (Coplan et al., 2000) and several human studies have found greater HPA activation and noradrenergic activation in the same subjects (Valdivieso et al., 1996; Wong et al., 2000; Roy et al., 1986, 1988; Rubin et al., 1985; Maes et al., 1991) although most studies did not report the correlation, if any, in normal subjects. Very few studies have utilized probes of both systems in the same individuals across diagnostic categories. To further explore system linkages and the impact of psychiatric disorders on them, we examined both stress systems in the same individuals, comparing subjects with an anxiety disorder, with depression, and with both anxiety and depression to matched groups of healthy controls. We used clonidine stimulated $\mathrm{GH}$ as an index of chronic noradrenergic activation, and response to the Trier Social Stress Test (TSST) to measure HPA axis reactivity.

\section{Methods}

\subsection{Subjects}

All studies were approved by the University of Michigan IRB. Subjects gave informed consent for a 'public speaking task' and the clonidine administration procedure. Subjects with major depression and anxiety disorders and normal controls were recruited by advertising from the community. After initial screening, the SCID-IV was administered by a trained research nurse, and subjects meeting inclusion/exclusion criteria were recruited into the study. A 'pure' depression group $(n=13)$ was composed of subjects who had Major Depressive Disorder (MDD) and did not meet current or past DSM-IV criteria for any anxiety disorder. A 'pure' anxiety group $(n=15)$ was composed of subjects who met DSM-IV criteria for an anxiety disorder (Panic, or Social Anxiety Disorder), with no current or recent past depression. Four of the subjects included in this group had a past episode of major depression, but these occurred a minimum of 2 years prior to the study and in all cases the anxiety disorder predated the depressive episode. A comorbid group $(n=17)$ was composed of subjects who met criteria for either a current anxiety or depressive disorder and also met criteria currently or within the past 6 months for a disorder from the other category. All 17 actually had both current anxiety and current depression at time of recruitment into the study. One patient with panic experienced reduced frequency of attacks after enrollment and prior to study. Two subjects experience partial improvement in depressive symptoms such that they no longer met full criteria for a major depressive episode at the time of the challenges. All subjects were free of all medication, including oral contraceptives and over the counter herbal remedies. Subjects were also excluded if alcohol intake was greater than seven drinks per week or if caffeine intake was greater than two cups of coffee or caffeine containing drinks per day. Cigarette smokers were excluded. Only five of 
the subjects had ever received psychotropic medications and the most recent exposure in any subject was 9 months prior to study. The numbers of subjects in the three psychiatric groups differ from the previous reports (Young et al., 2004; Cameron et al., 2004), because not all subjects completed both challenges. Normal subjects were individually matched on sex and age and were free of all psychiatric diagnoses, in themselves and their firstdegree relatives.

\subsection{Challenge procedures}

All subjects participated in both challenges: clonidine infusion with measurement of growth hormone to assess the noradrenergic system, and the Trier Social Stress Test (TSST) for measurement of ACTH and cortisol response to an emotional stressor. The challenges were carried out in random order on separate days at least 2 days apart (average $13 \pm 12$ (SD) days).

\subsubsection{TSST}

At $1430 \mathrm{~h}$ on the day of study, subjects reported to a neuroendocrine study suite at the University of Michigan Depression Program. They were placed supine in bed and an intravenous catheter was inserted for blood drawing. Beginning at 15:00 h, and continuing until 60 min after task completion, blood was drawn every $10 \mathrm{~min}$ for ACTH and cortisol. At $15: 30 \mathrm{~h}$, subjects were moved to another room for the TSST, a public speaking task involving a mock job interview and mental arithmetic (Kirschbaum et al., 1993; Young et al., 2004). Following completion of the stress session, subjects were then allowed to rest quietly for an hour, until blood sampling was completed.

\subsubsection{Clonidine stimulated $\mathrm{GH}$}

Subjects were admitted to a Clinical Research Center at 07:30 h and an intravenous catheter for blood draws and clonidine infusion was inserted within $30 \mathrm{~min}$. They were kept at bed rest. Starting at 09:00 h, clonidine $(2 \mathrm{mcg} / \mathrm{kg})$ was administered intravenously over 5 min by infusion pump. Samples for $\mathrm{GH}$ were drawn 30,15, and 1 min before the infusion and 15, 30, 60, 90, and 120 min after its completion. Symptom severity ratings (Hamilton Depression and Anxiety Rating Scales) were completed on the day of the study.

\subsection{Hormone assay}

Samples were immediately placed on ice after being drawn. Those for ACTH and cortisol were centrifuged within 10 min of collection and those for $\mathrm{GH}$ within $30 \mathrm{~min}$. Plasma was then frozen at $70^{\circ}$ until assay. Subjects and their matched controls were paired for all assays. Cortisol was assayed using DPC (Los Angeles, CA) Coat-a-Count kits. ACTH was assayed using Allegro HS IRMA (Nichols Diagnostic Institute, San Juan Capistrano, CA). Inter-assay variability for ACTH was $7.3 \%$ and for cortisol was $5 \%$. GH samples were assayed by the Nichols IRMA method, with an inter-assay coefficient of variation of $6.8 \%$.

\subsection{Statistical analyses}

Area under the curve (AUC) was calculated for each hormone, using trapezoidal approximation after subtracting a baseline value from each measure. Since the accommodation period was relatively short and varied between challenges and recovery periods were relatively long, we utilized the lowest level achieved for each hormone during any phase of the study as that subject's 'baseline'. AUCs were natural log transformed and then subjected to linear regression analyses, focusing on relationships between responses to the TSST and responses to clonidine. Individual matching of normal subjects to patients controlled for age, sex, and assay variability, so covariates for these measures were not utilized. In order to limit the total number of regression analyses run for this report, we focused on the two measures which revealed the most meaningful group differences in the above results: ACTH response to the TSST and GH response to clonidine. Challenge order did not affect results of either challenge and was therefore also ignored in these analyses.

\section{Results}

Table 1 presents the demographic and clinical data for all subjects who underwent both challenges. Results of each challenge have been previously reported (Young et al., 2004; Cameron et al., 2004) and will only be briefly summarized here. On the TSST, subjects with comorbid depression and anxiety demonstrated an exaggerated ACTH response to psychosocial challenge, whereas both pure anxiety and pure depression subjects showed normal responses. On the clonidine test, the pure anxiety group demonstrated a blunted $\mathrm{GH}$ response while the pure depressed group demonstrated a normal response and the comorbid group appeared intermediate. Tables $2 \mathrm{~A}$ and $\mathrm{B}$ presents the regression data for clonidine stimulated $\mathrm{GH}$ and 
Table 1 Characteristics of the depressed (MDD), anxiety and control group.

\begin{tabular}{lllll}
\hline & Pure MDD & Comorbid MDD & Pure anxiety & Controls \\
\hline Number of subjects & 13 & 17 & 15 & 45 \\
Age & $28.2 \pm 7.7$ (SD) & $23.2 \pm 5.5$ & $25.4 \pm 8.5$ & $25.8 \pm 7.1$ \\
Sex F:M & $7: 6$ & $13: 4$ & $8: 7$ & $26: 19$ \\
Hamilton depression rating & $18.3 \pm 3.7$ (SD) & $12.76 \pm 6.9$ (SD) & $3.3 \pm 3.4($ SD) & $0.5 \pm 0.9$ (SD) \\
Hamilton anxiety rating & $12.7 \pm 3.8$ (SD) & $12.3 \pm 7.2($ SD) & $5.8 \pm 7$ (SD) & $0.7 \pm 0.7$ (SD) \\
Anxiety diagnoses & 0 & 17 & 15 & 0 \\
Panic disorder & 0 & 4 & 3 & 0 \\
Social phobia & 0 & 13 & 12 & 0 \\
PTSD & 0 & $2^{\mathrm{a}}$ & $1^{\mathrm{a}}$ & 0 \\
AUC ACTH & $133 \pm 122$ & $262 \pm 308$ & $181 \pm 163$ & $196 \pm 175(\mathrm{SD})$ \\
AUC GH & $275 \pm 208$ & $238 \pm 256$ & $173 \pm 146$ & $306 \pm 298$ (SD) \\
\hline
\end{tabular}

${ }^{a}$ Also met criteria for panic disorder (1) and social phobia (1) in comorbid group and social phobia in anxiety group.

TSST stimulated ACTH. There was a significant correlation $(r=-0.4)$ between these two systems in the control subjects (Tables $2 \mathrm{~A}$ and $\mathrm{B}$, Fig. 1). The correlation is negative, indicating that a larger $\mathrm{ACTH}$ response to the stressor was associated with a smaller $\mathrm{GH}$ response to clonidine. We examined whether gender influenced the correlation, but because of reduced power, only females demonstrated a significant correlation although the actual correlation coefficient was very similar for males and females. (females: $r=0.41, F=4.72, d f=1$, $p=0.04$; males $r=0.416, F=3.56, \mathrm{~d} f=1, p=0.07$ ). While a significant correlation was observed in the control subjects, the correlation between systems in the patient group was not significant $(r=-0.2$, Fig. 2). When the three diagnostic groups were examined separately, the pure anxiety group, like the normal subjects, showed a significant correlation between systems. (Tables $2 \mathrm{~A}$ and B, Fig. 3) This normal relationship was lost in the depressed subjects, whether examining pure depressed subjects alone or those with a comorbid anxiety disorders (Tables 2A and B). The normal linkage between systems was disrupted in the pure depressed group despite the fact that they showed a normal $\mathrm{GH}$ response to clonidine (Cameron et al.,

Table 2A Correlation coefficients of In AUC ACTH with In AUC GH.

\begin{tabular}{llll}
\hline Group & Correlation & $F$ & $P$ \\
\hline All controls & -0.425 & 9.49 & 0.0036 \\
All patients & -0.208 & 1.95 & 0.17 \\
Pure anxiety & -0.563 & 6.02 & 0.03 \\
Pure depression & -0.049 & 0.03 & 0.87 \\
Comorbid & -0.205 & 0.66 & 0.43 \\
anxiety and & & & \\
depression & & & \\
\hline
\end{tabular}

2004), and normal ACTH response to the stressor (Young et al., 2004). The linkage was also disrupted in the comorbid group, which showed an exaggerated ACTH response to the TSST but a normal GH response to clonidine. Because the time between challenges varied among subjects, we examined whether subjects whose challenges were more than 1 week apart demonstrated a loss of this correlation. Subjects studied within 7 days (mean 4.6士 2.1 days (SD), $n=18$ ) demonstrated a correlation of $0.555(F=7.12, p=0.01)$ while subjects studied more than 1 week apart (mean $=18.6 \pm 8.8$ days, $n=26)$ still demonstrated a correlation of 0.35 , which was significant at the trend level $(F=3.39$, $p=0.07$ ).

We also examined whether there was a significant relationship between AUC cortisol and AUC $\mathrm{GH}$. In no case examined (all subjects, all controls, all patients or subgroup of patients) was a significant correlation observed between In AUC GH and In AUC cortisol. This absence of correlation occurred despite a highly significant correlation of AUC ACTH and AUC cortisol ( $r=0.64, F=58.45, p=$ 0.0001 ). We also found no relationship between baseline (pre-TSST) In cortisol or In ACTH and In AUC GH.
Table 2B Correlation coefficients of In AUC cortisol with In AUC GH.

\begin{tabular}{llll}
\hline Group & Correlation & $F$ & $P$ \\
\hline All controls & -0.119 & 0.588 & 0.45 \\
All patients & -0.152 & 0.975 & 0.33 \\
Pure anxiety & -0.256 & 0.771 & 0.40 \\
Pure depression & -0.238 & 0.723 & 0.41 \\
Comorbid anxiety & -0.042 & 0.025 & 0.88 \\
and depression & & & \\
\hline
\end{tabular}




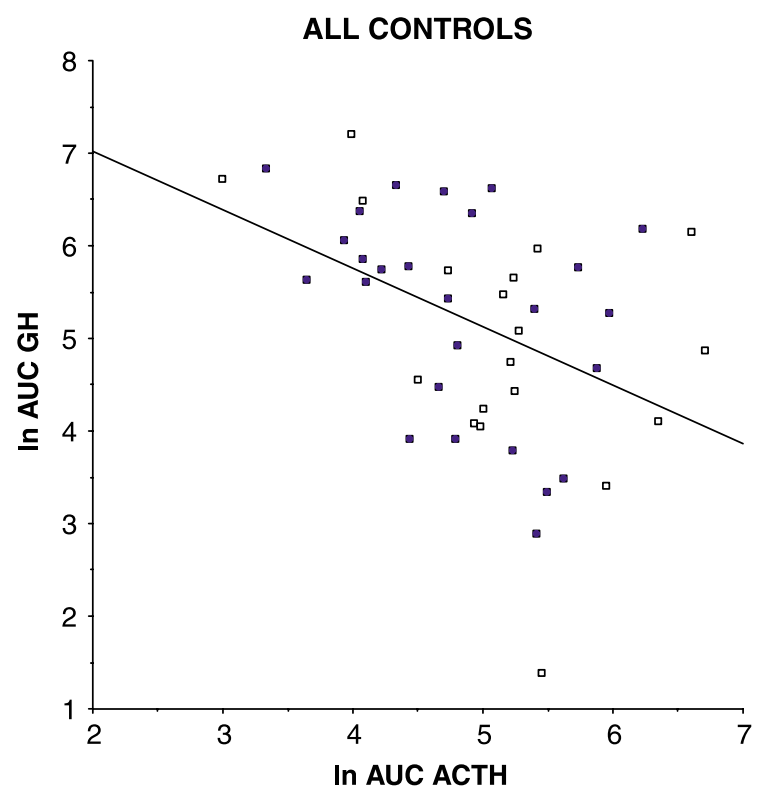

Figure 1 Scatter plot with regression line for the relationship between $\mathrm{ACTH}$ response to the TSST and $\mathrm{GH}$ response to clonidine in control subjects. Males are indicated by the open squares and females by the filled squares. AUC have been log transformed prior to plotting to normalize distribution of hormones. A significant relationship was found in normal subjects.

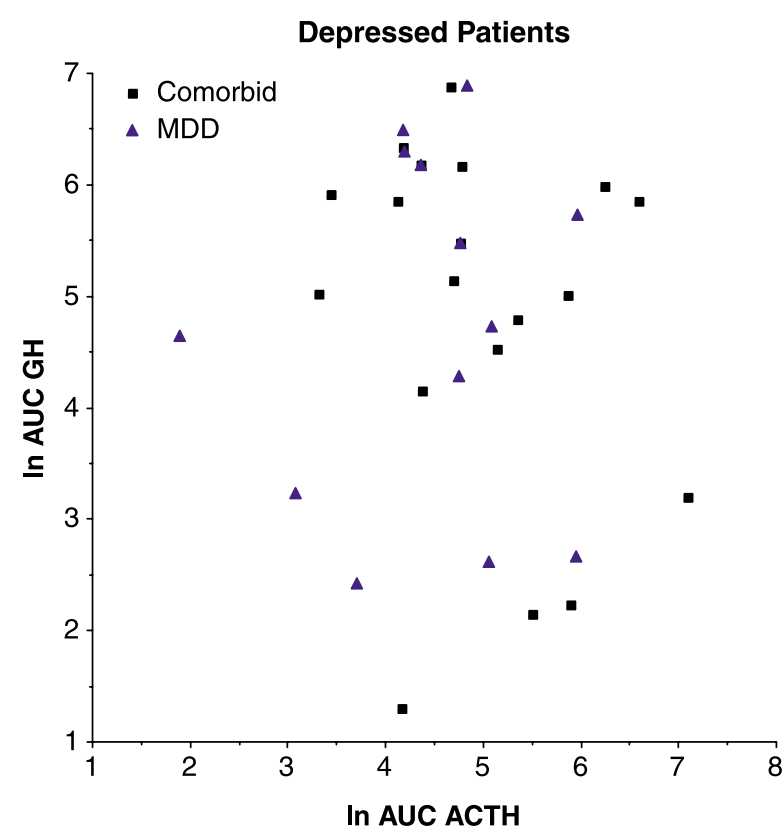

Figure 2 Scatter plot of the relationship between ACTH response to the TSST and $\mathrm{GH}$ response to clonidine in depressed patients, pure (MDD, triangles) and comorbid (squares). AUC have been log transformed prior to plotting to normalize distribution of hormones. There is no significant relationship in the depressed patient group.

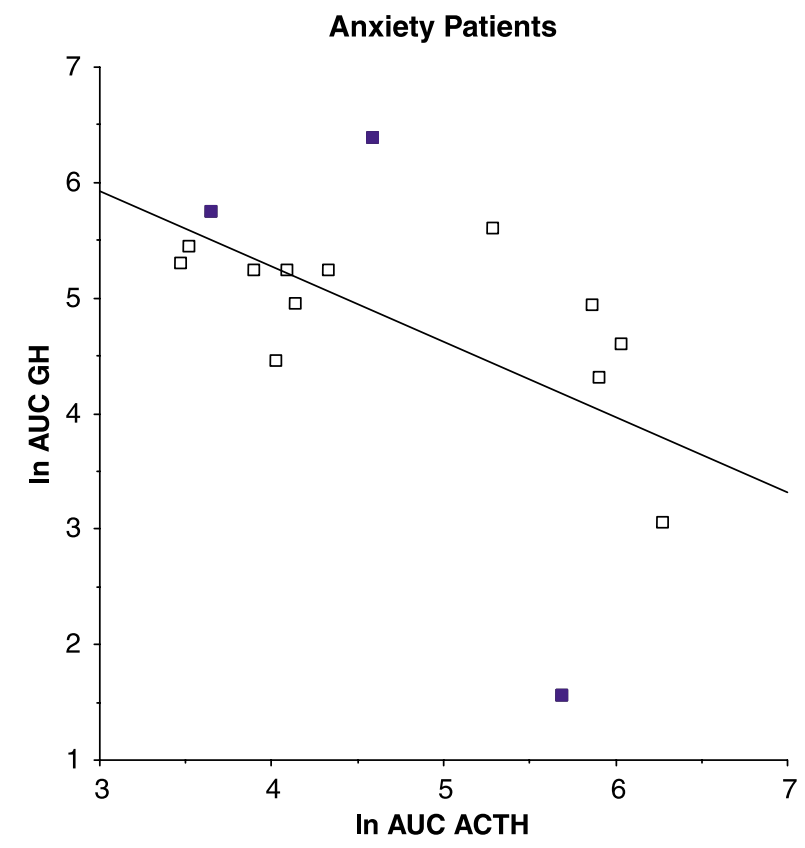

Figure 3 Scatter plot with regression line for the relationship between $\mathrm{ACTH}$ response to the TSST and $\mathrm{GH}$ response to clonidine in the pure anxiety subjects. AUC have been log transformed prior to plotting to normalize distribution of hormones. The patients with social phobia are shown with open squares and panic disorder subjects with filled squares. A significant correlation was observed in the pure anxiety group.

\section{Discussion}

This study, examining challenges to two stressactivated systems, demonstrated an inverse correlation between clonidine stimulated $\mathrm{GH}$ secretion and $\mathrm{ACTH}$ response to an emotional stressor in normal subjects. To the extent that $\mathrm{GH}$ response to clonidine reflects $\alpha 2$-noradrenergic receptor sensitivity and thus tonic LC noradrenergic activity (see Abelson et al., 2005 for a complete discussion) the negative correlation suggests that the magnitude of the ACTH response to the stressor is inversely related to noradrenergic basal tonic activity. Consequently, within normal subjects those individuals who show low tonic noradrenergic activity and normal $\alpha 2$-noradrenergic receptor sensitivity would demonstrate a larger GH response to clonidine and a smaller ACTH response on the TSST challenge compared with individuals with elevated noradrenergic tone and the consequent $\alpha$-noradrenergic receptor desensitization leading to smaller $\mathrm{GH}$ response to clonidine. Furthermore, the latter finding would be associated with larger ACTH stress responses to the TSST challenge. Thus, reactivity to a stressor is linked to average basal noradrenergic activity, indicating that noradrenergic input may 
contribute to the acute ACTH response to stress. The fact that the two challenges were administered more than 1 week apart supports the idea that the linkage reflects stable characteristics of these systems within individuals. The finding of a significant relationship between systems confirms basic animal studies demonstrating that these systems are two arms of a coordinated central stress response (Sved et al., 2002; Dunn and Berridge, 1990; Valentino et al., 1991).

Our data suggest that the normal inverse relationship between systems observed in normal subjects is maintained in anxiety disorders, even though subjects with anxiety disorders as a group show smaller responses to clonidine than normal subjects. The blunted $\mathrm{GH}$ responses suggest noradrenergic hyperactivity (Cameron et al., 2004), and a preserved relationship with the HPA axis would therefore predict abnormal sensitivity in this system as well; but pure anxiety patients did not show significantly elevated HPA responses to the TSST (Young et al., 2004). However, this correlation is within the group and thus only indicates that those individuals with the most blunted $\mathrm{GH}$ response to clonidine show the largest ACTH response to the TSST, whether or not their response is 'normal'.

In major depression, in contrast to anxiety disorders, the normal relationship between tonic LC activity and HPA axis activation appears to be altered. The relationship is disrupted in both the comorbid group, which demonstrated an exaggerated ACTH response to the stressor, and the pure depressed group, which demonstrated a normal response to the stressor. If we assume that depression is accompanied by normal LC activity (as shown by a normal GH response to clonidine in these depressed patients) but that the HPA axis is overactive, then the dissociation of these two systems in depression would be expected.

We were able to observe a significant relationship between AUC GH and AUC ACTH but not AUC $\mathrm{GH}$ and $\mathrm{AUC}$ cortisol, despite the strong correlation between AUC cortisol and AUC ACTH. These data suggest that other factors (such as adrenal sensitivity to ACTH) may modulate the cortisol response to the stressor that leads the cortisol response to be less tightly correlated to central noradrenergic tone than ACTH. It is also of note that our differences among diagnostic groups in response to the TSST were observed primarily with ACTH and no significant differences were observed with cortisol response. It may be that ACTH better reflects acute dynamics of this system, which would be modulated by LC/noradrenergic activity while cortisol is responding over a longer time frame.
One possible mechanistic explanation for the dissociation of these systems in depression could involve the role of cortisol. Since depression is associated with increased basal cortisol, and cortisol will inhibit LC activity (Mc Ewen, 1995; Watanabe et al., 1995), it is possible that increased cortisol will 'correct' (i.e. decrease) increased LC activation that may occur transiently during depression. In contrast, there is little evidence of chronic hypercortisolemia in anxiety disorders, so in this group the chronic activation of the LC would not be restrained by cortisol. These findings suggest that in depression, the $\mathrm{CRH}$ activation that drives the HPA axis is not associated with activation of brainstem $\mathrm{CRH}$ pathways regulating the $\mathrm{LC}$.

Several studies have examined the relationship between basal cortisol or post-dexamethasone cortisol and a measure of noradrenergic activity such as plasma MHPG. CSF NE or urinary metabolites of norepinephrine and urinary free cortisol (Roy et al., 1986, 1988; Rosenbaum et al., 1983; Rubin et al., 1985; Maes et al., 1991; Wong et al., 2000). In contrast to our findings, most have shown a positive relationship between elevated cortisol and measures of noradrenergic activation in patients with melancholic depression. The inverse relationships we found involved ACTH, not cortisol, and we believe this reflects mechanisms of acute regulatory control in an activation paradigm. Different neural mechanisms are likely to be involved when measuring basal activity using measures like cortisol that integrate activity over longer time frames. The study of Coplan et al. (1995) examined the MHPG and cortisol response to clonidine and found correlations in normal subjects, which were not found in a group with panic disorder. Whether the use of a different challenge or a different anxiety group (panic disorder) accounts for the difference in findings between our study and their study is not clear. Both of our challenges were stimulatory while Coplan et al. were examining inhibition of basal circadian cortisol activity, which may involve different neural pathways than stress activated cortisol secretion. We were examining relationships across challenges, while Coplan et al. looked within a single challenge. Finally, our challenge looked at acute reactivity to stress in relationship to chronic activation of noradrenergic systems, which may be different than acute effects of clonidine on cortisol.

In conclusion, our data suggest a clear inverse relationship between tonic activity of the LC noradrenergic system and the ACTH response to a stressor. This suggests that under normal circumstances, noradrenergic systems can influence the magnitude of the HPA axis response to stress. This relationship observed in normal subjects was 
preserved in subjects with an anxiety disorders but disrupted by major depression, even in subjects with primary anxiety disorders that developed a depressive episode. Consequently, in subjects with major depression, HPA axis activation in response to a stressor appears autonomous of noradrenergic influence. The mechanism whereby depression may disrupt this relationship is unknown. Because insensitivity of the HPA axis to glucocorticoid negative feedback is a frequent occurrence (Young et al., 1991, 1993, 2000), while the sequellae of increased cortisol have been found on other systems in major depression. (Gold and Chrousos, 1999), it is possible that elevated basal cortisol of depression may restrain the noradrenergic system without adequately restraining the HPA axis.

\section{Acknowledgements}

The authors would like to acknowledge the support of MH57751 (all authors), MH 01931 to EAY, MO1 RR00042 (General Clinical Research Center (G-CRC) of the University of Michigan), the nursing staff of the G-CRC and Kathleen Singer RN for help in conducting these studies.

\section{References}

Abelson, J.L., Cameron, O.G., 1994. Adrenergic dysfunction in anxiety disorders. In: Cameron, O.G. (Ed.), Adrenergic Dysfunction and Psychobiology. American Psychiatric Press, Washington, DC.

Abelson, J.L., Curtis, G.C., 1996. Hypothalamic-pituitaryadrenal axis activity in panic disorder: 24-hour secretion of corticotropin and cortisol. Arch. Gen. Psychiatry 53, 323-331.

Abelson, J.L., Curtis, G.C., Uhde, T.W., 2005. Twenty-four hour growth hormone secretion in patients with panic disorder. Psychoneuroendocrinology 30, 72-79.

Amsterdam, J.D., Maislin, G., Skolnick, B., Berwish, N., Winokur, A., 1989. Multiple hormone responses to clonidine administration in depressed patients and healthy volunteers. Biol. Psychiatry 26, 265-278.

Aston Jones, G., Shipley, M.T., Chouvet, G., et al., 1991. Afferent regulation of locus coeruleus neurons: anatomy, physiology and pharmacology. Prog. Brain Res. 88, 47-75.

Cameron, O.G., Abelson, J., Young, E.A., in press. Anxious and depressive disorders and their comorbidity: effect on central nervous system noradrenergic function. Biol. Psychiatry 56, 875-883.

Charney, D.S., Heninger, G.R., 1986. Abnormal regulation of noradrenergic function in panic disorder. Arch. Gen. Psychiatry 43, 1042-1054.

Charney, D.S., Heninger, G.R., Sternberg, D.E., Hafstad, K.M., Giddings, S., Landis, D.H., 1982. Adrenergic receptor sensitivity in depression: effects of clonidine in depressed and healthy subjects. Arch. Gen. Psychiatry 39, 290-294.
Commons, K.G., Connalle, K.R., Valentino, R.J., 2003. A neurochemically distinct dorsal raphe-limbic circuit with a potential role in affective disorders. Neuropsychopharmacology 28, 206-215.

Coplan, J.D., Pine, D., Papp, L., Martinez, J., Cooper, T., Rosenblum, L.A., Gorman, J.M., 1995. Uncoupling of the noradrenergic-hypothalamic-pituitary-adrenal axis in panic disorder patients. Neuropsychopharmacology 13, 65-73.

Coplan, J.D., Smith, E.L., Trost, R.C., Scharf, B.A., Altemus, M., Bjornson, L., Owens, M.J., Gorman, J.M., Nemeroff, C.B., Rosenblum, L.A., 2000. Growth hormone response to clonidine in adversely reared young adult primates: relationship to serial cerebrospinal fluid corticotropin-releasing factor concentrations. Psychiatry Res. 95, 93-102.

Curtis, A.L., Bello, N.T., Connolly, K.R., Valentino, R.J., 2002. Corticotropin-releasing factor neurones of the central nucleus of the amygdala mediate locus coeruleus activation by cardiovascular stress. J. Neuroendocrinol. 14, 667-682.

Devesa, J., Arce, V., Lois, N., Tresguerres, A.F., Lima, L., 1990. Alpha2-adrenergic agonism enhances the growth hormone (GH) response to $\mathrm{GH}$-releasing hormone through an inhibition of hypothalamic somatostatin release in normal men. J. Clin. Endocrinol. Metab. 71, 1581-1588.

Devesa, J., Diaz, M.J., Tresguerres, J.A.F., Arce, V., Lima, L., 1991. Evidence that alpha2-adrenergic pathways play a major role in growth hormone $(\mathrm{GH})$ neuroregulation: alpha2adrenergic agonism counteracts the inhibitory effect of muscarinic cholinergic receptor blockade on the $\mathrm{GH}$ response to GH-releasing hormone, while alpha2-adrenergic blockade diminishes the potentiating effect of increased cholinergic tone on such stimulation in normal men. J. Clin. Endocrinol. Metab. 73, 251-256.

Dunn, A.J., Berridge, C.W., 1990. Physiological and behavioral responses to corticotropin-releasing factor administration: is CRF a mediator of anxiety or stress response. Brain Res. Rev. 15, 71-100.

Gold, P.W., Chrousos, G.P., 1999. The endocrinology of melancholic and atypical depression: relation to neurocircuitry and somatic consequences. Proc. Assoc. Am. Physicians 111, 22-34.

Kirschbaum, C., Pirke, K.M., Hellhammer, D.H., 1993. The 'Trier Social Stress Test'-a tool for investigating psychobiological stress responses in a laboratory setting. Neuropsychobiology 28, 76-81.

Maes, M., Minner, B., Suy, E., Vandervorst, C., Raus, J., 1991. Coexisting dysregulations of both the sympathoadrenal system and hypothalamic-pituitary-adrenal-axis in melancholia. J. Neural Trans. Gen. Sect. 85, 195-210.

Makino, S., Gold, P.W., Schulkin, J., 1994. Corticosterone effects on corticotropin-releasing hormone mRNA in the central nucleus of the amygdala and the parvocellular region of the paraventricular nucleus of the hypothalamus. Brain Res. 640, 105-112.

Mc Ewen, B.S., 1995. Adrenal steroid action on brain: dissecting the fine line between protection and damage. In: Friedman, M.J., Charney, D.S., Deutch, A.Y. (Eds.), Neurobiological and Clinical Consequences of Stress: From Normal Adaptation to PTSD. Lippincott-Raven, Philadelphia, PA.

Nutt, D.J., 1989. Altered central alpha2-adrenoreceptor sensitivity in panic disorder. Arch. Gen. Psychiatry 46, 165-169.

Pacak, K., Palkovits, M., 2001. Stressor specificity of central neuroendocrine responses: implications for stress-related disorders. Endocr. Rev. 22, 502-548.

Plotsky, P.M., 1987. Facilitation of immunoreactive corticotropin-releasing factor secretion into the hypophyseal-portal 
circulation after activation of catechoaminergic pathways or central norepinepherine injection. Endocrinology 121, 924-930.

Rosenbaum, A.H., Maruta, T., Schatzberg, A.F., Orsulak, P.J., Jiang, N.S., Cole, J.O., Schildkraut, J.J., 1983. Toward a biochemical classification of depressive disorders, VII: urinary free cortisol and urinary MHPG in depressions. Am. J. Psychiatry 140, 314-318.

Roy, A., Agren, H., Pickar, D., Linnoila, M., Doran, A.R., Cutler, N.R., Paul, S.M., 1986. Reduced CSF concentrations of homovanillic acid and homovanillic acid to 5-hydroxyindoleacetic acid ratios in depressed patients: relationship to suicidal behavior and dexamethasone nonsuppression. Am. J. Psychiatry 143, 1539-1545.

Roy, A., Pickar, D., De Jong, J., Karoum, F., Linnoila, M., 1988. Norepinephrine and its metabolites in cerebrospinal fluid, plasma, and urine. Relationship to hypothalamic-pituitaryadrenal axis function in depression. Arch. Gen. Psychiatry 45 , 849-857.

Rubin, A.L., Price, L.H., Charney, D.S., Heninger, G.R., 1985. Noradrenergic function and the cortisol response to dexamethasone in depression. Psychiatry Res. 15, 5-15.

Siever, L.J., Uhde, T.W., Silberman, E.K., Jimerson, D.C., Aloi, J.A., Post, R.M., Murphy, D.L., 1982. Growth hormone response to clonidine as a probe of noradrenergic receptor responsiveness in affective disorder patients and controls. Psychiatry Res. 6, 171-183.

Sved, A.F., Cano, G., Passerin, A.M., Rabin, B.S., 2002. The locus coeruleus, Barrington's nucleus, and neural circuits of stress. Physiol. Behav. 77, 737-742.

Uhde, T.W., Vittone, B.J., Siever, L.J., Kaye, W.H., Post, R.M., 1986. Blunted growth hormone response to clonidine in panic disorder patients. Biol. Psychiatry 21, 1081-1085.

Valdivieso, S., Duval, F., Mokrani, M.C., Schaltenbrand, N., Castro, J.O., Crocq, M.A., Macher, J.P., 1996. Growth hormone response to clonidine and the cortisol response to dexamethasone in depressive patients. Psychiatry Res. 60, 23-32.
Valentino, R.J., 1989. Corticotropin-releasing factor: putative neurotransmitter in the noradrenergic nucleus locus coeruleus. Psychoparmacol. Bull. 25, 306-311.

Valentino, R.J., Page, M.E., Curtis, A.L., 1991. Activation of noradrenergic locus coeruleus neurons by hemodynamic stress is due to local release of corticotropin-releasing factor. Brain Res. 555, 25-34.

Watanabe, Y., McKittrick, C.R., Blanchard, D.C., Blanchard, R.J., McEwen, B.S., Sakai, R.R., 1995. Effects of chronic social stress on tyrosine hydroxylase mRNA and protein levels. Brain Res. Mol. Brain Res. 32, 176-180.

Watson, S., Porter, R.J., Young, A.H., 2000. Effect of hydrocortisone on the pituitary response to growth hormone releasing hormone. Psychopharmacology (Berl) 152, 40-46.

Wong, M.L., Kling, M.A., Munson, P.J., Listwak, S., Licinio, J., Prolo, P., Karp, B., McCutcheon, I.E., Geracioti Jr.., T.D., DeBellis, M.D., Rice, K.C., Goldstein, D.S., Veldhuis, J.D., Chrousos, G.P., Oldfield, E.H., McCann, S.M., Gold, P.W., 2000. Pronounced and sustained central hyper-noradrenergic function in major depression with melancholic features: relation to hypercortisolism and corticotropin-releasing hormone. Proc. Natl Acad. Sci. USA 97, 325-330.

Young, E.A., Haskett, R.F., Watson, S.J., Akil, H., 1991. Loss of Glucocorticoid Fast Feedback in Depression. Arch. Gen. Psychiatry 48, 693-699.

Young, E.A., Kotun, J., Haskett, R.F., Grunhaus, L., Greden, J.F., Watson, S.J., Akil, H., 1993. Dissociation between pituitary and adrenal suppression to dexamethasone in depression. Arch. Gen. Psychiatry 50, 395-403.

Young, E.A., Lopez, J.F., Murphy-Weinberg, V., Watson, S.J., Akil, H., 2000. Hormonal evidence for altered responsiveness to social stress in major depression. Neuropsychopharmacology 23, 411-418.

Young, E.A., Abelson, J.L., Cameron, O.G., 2004. Effect of comorbid anxiety disorders on the HPA axis response to a social stressor in major depression. Biol. Psychiatry 56, 113-120.

Available online at www.sciencedirect.com

science Wirect 